\title{
SOBRE A ATUALIDADE DO CONCEITO DE INDÚSTRIA CULTURAL
}

AnTônio Álvaro SoARes Zuin*

$A$ verdade que, evidentemente, após a reincidência da barbárie não mais pode ser identificada com o belo e o bom, vive nos exageros da Teoria Crítica da sociedade.

(Detlev Claussen)

RESUMO: Este texto objetiva argumentar que a essência do conceito de Indústria Cultural não só permanece atual, como também é relevante para a crítica das condições sociais que fundamentam a universalização da semiformação (Halbbildung). Conclui-se que uma concepção educacional crítica, balizada nos escritos de Theodor W. Adorno, poderia oferecer subsídios iniciais para uma práxis de resistência a esse processo de debilitação da individualidade.

Palavras-chave: Indústria Cultural, Formação, Semiformação, Theodor W. Adorno, Teoria Crítica.

$\mathrm{O}$ atual desenvolvimento dos meios de comunicação de massa recrudesce a sensação da inexistência de qualquer tipo de obstáculo que poderia impedir as trocas de diferentes produções e valores culturais dos mais variados países do globo. Diante da possibilidade da realização dos contatos via on line, os mesmos olhares embasbacados frente à tela do computador revelam, de soslaio, o brilho da desconfiança ou mesmo da indiferença quando se deparam com um conceito tal como o de Indústria Cultural. Em uma sociedade tecnificada, nada é mais inconveniente do que a insistência, para muitos anacrônica, da reflexão crítica de que a massificação e consumo da produção cultural não implicam a concretização de uma sociedade mais justa e democrática.

Mas a fetichização da técnica e a reificação das consciências teimam em nos lembrar que as reconciliações entre o indivíduo e a sociedade, entre

\footnotetext{
* Professor Adjunto do Departamento de Educação da UFSCar e um dos coordenadores do grupo de estudos e pesquisa: Teoria Crítica e Educação (UFSCar, Unimep e Unesp/Araraquara). E-mail: dazu@power.ufscar.br
} 
o desejo e a cultura não foram ainda efetivadas. O que atualmente se realiza, no dizer de Adorno, é a reconciliação forçada. Engana-se o discurso oficial que se aferra exclusivamente na evidente deficiência da escolarização formal como a causa dos problemas sociais que são vivenciados cotidianamente. Por outro lado, é também falso o arrazoado que defende a idéia de que esses mesmos problemas seriam resolvidos através do progressivo desenvolvimento linear de uma educação elementar para uma educação que produzisse pessoas consideradas cultas.

Infelizmente, essas veleidades são corriqueiramente desmentidas por acontecimentos inconcebíveis, tal como o assassinato do índio Galdino, da tribo pataxó, que foi queimado vivo por adolescentes bem nutridos e com um alto nível de escolarização formal. Quando um ato de vandalismo como esse é justificado pelos assassinos como uma brincadeira infeliz, a ponto de ser inocentado pela justiça que se compraz com essa racionalização, então justifica-se cada vez mais a necessidade de se depreender os elementos objetivos e, principalmente, subjetivos atrelados às causas da barbárie.

Tais atos são indicativos de que há uma nítida fissura entre os conteúdos ideológicos da promessa de uma vida mais justa por causa da "democratização da cultura" e o real cumprimento dessa intenção. De fato, a produção cultural que se submete quase que por completo ao seu caráter de valor afasta-se de si própria, ou seja, termina por negar toda possibilidade de felicidade ao dissimular um verdadeiro estado de liberdade.

Desta forma, este texto objetiva argumentar que a essência do conceito de Indústria Cultural não só permanece atual, como também é relevante para a crítica das condições sociais que fundamentam a universalização da semiformação (Halbbildung). Procura-se também asseverar que uma concepção educacional crítica, balizada nos escritos de Theodor W. Adorno, poderia oferecer subsídios iniciais para uma práxis de resistência a esse processo de debilitação da individualidade.

Compreende-se o conceito semiformação justamente pela tentativa de oferecimento de uma formação educacional que se faz passar pela verdadeira condição de emancipação dos indivíduos quando, na realidade, contribui decisivamente tanto para a reprodução da miséria espiritual como para a manutenção da barbárie social. E o contexto social no qual a barbárie é continuamente reiterada é o da indústria cultural hegemônica. ${ }^{1}$

$\mathrm{O}$ conceito de Indústria Cultural foi exposto por Adorno e Horkheimer no livro Dialética do esclarecimento: Fragmentos filosóficos. A sua profundidade pode ser identificada justamente naquilo que possui de mais ambíguo, pois se ambos os termos - indústria e cultura - são inter- 
dependentes, contudo não se realizam completamente. De acordo com Adorno, a Indústria Cultural se assemelha a uma indústria quando destaca a estandardização de determinado objeto - os filmes de gênero western, por exemplo - e quando diz respeito à racionalização das técnicas de distribuição.

Entretanto, ela não se reduz ao termo indústria pois não se refere apenas ao processo de produção. Se podemos observar um nítido processo de divisão de trabalho, de introdução de máquinas e de separação dos trabalhadores em relação aos meios de produção quando investigamos um filme (o setor central da Indústria Cultural), por outro lado, cada objeto carrega em si a marca de sua individualidade (Adorno, 1986, p. 94). E se tal objeto, ao portar algum traço característico que o faz distinguir-se do demais, permite ao sujeito alguma forma de intervenção na sociedade, fazendo crer que a hegemonia da indústria sobre a cultura não seja tão determinante, a ilusão se esfacela quando as particularidades engendradas nada mais são do que mercadorias padronizadas que podem ser trocadas e que cobram seus dividendos na consolidação da sua individualidade danificada.

Tal debilitação da individualidade é o resultado de um processo social que tem como principal característica a universalização do princípio da lógica da mercadoria, tanto na dimensão objetiva como na subjetiva. A lógica do equivalente acaba por fundamentar os alicerces do raciocínio dicotômico que consagra os rótulos daqueles que são considerados "perdedores" ou "vencedores", por exemplo. Dificulta-se a sobrevivência do pensamento crítico numa sociedade em que os indivíduos se transformam em "caixas de ressonância” de mensagens que seduzem pelo incentivo à integração, muitas vezes cega, a um coletivo regido por uma palavra de ordem autoritária. Quando as pessoas se dessensibilizam em relação aos outros e em relação a si próprias, ou quando os objetos são construídos sem o objetivo de auxiliar a composição de uma vida melhor para todos, estamos diante de um sistema social cujas relaçóes favorecem um clima cultural simpático à reincidência de fatos tais como o assassinato do índio pataxó.

É importante destacar que quando Adorno alude para as conseqüências da fetichização da técnica no plano subjetivo não significa que ocorra qualquer tipo de defesa do desejo de mudança alicerçado numa conotação sentimental. As conseqüências provenientes do fato das pessoas se sensibilizarem em relação aos objetos, a ponto da afetividade ser trocada como qualquer outro tipo de mercadoria, não podem ser neutralizadas mediante o sorriso de contentamento do indivíduo que pensa que vale tanto quanto o dinheiro gasto na compra de seu presente. 
Antes de ser um comportamento engendrado por uma patologia idiossincrática, o apogeu do fenômeno da dessensibilização revela uma incapacidade de transferência da libido para as representaçōes de outras pessoas numa sociedade específica, ou seja, a sociedade do capitalismo transnacional. Desse modo, até mesmo a existência do esclarecimento (Aufklärung) encontra-se hoje determinada pela vontade de transformá-lo numa forma de show. Ao comentar a discussão atual sobre a chamada "noite dos cristais", ${ }^{2}$ Detlev Claussen assevera que:

O movimento hegemônico da indústria cultural, que culminou na solenidade de aniversário de cinqüenta anos da "noite dos cristais", mesclou a intenção do esclarecimento e a técnica da indústria cultural com a intenção de se conquistar o público. Por meio dessa mescla é consolidada a atitude ambivalente da maioria dos homens após Auschwitz, preservando neles próprios o anti-semitismo. (1990, p. 140)

Diante desse conturbado contexto, a mercantilização da produção simbólica possui duas tarefas fundamentais: a integração e a reconciliação forçada entre os grupos sociais desiguais entre si. Esse é o objetivo central do sistema de produção calcado na falsidade de que a massificação da cultura realmente possibilita a emancipação coletiva. Nesse reinado de clichês, tudo que possa vir a público já se encontra tão profundamente demarcado que nada pode surgir sem exibir de antemão os traços e os comportamentos demarcados pelo "gosto popular".

$\mathrm{Na}$ verdade, a ideologia encontra-se tão "colada" à realidade que qualquer comportamento que não se atrele ao atendimento das necessidades do consumo é rotulado como desviante. Não obstante, tem-se a impressão de que não há qualquer tipo de padronização ou uniformização do produto. Parece que vivenciamos uma identidade "única", já que nos diferenciamos de todos os outros que não usam nossas marcas sociabilizadoras, tais como as marcas dos tênis e grifes de roupas famosas.

Esta talvez seja a principal característica psicossocial do processo dissimulador da semiformação. O auspício inicial da formação burguesa - de que a sociedade democrática seria principalmente constituída por um indivíduo consciente das contradições entre os seus desejos e o desenvolvimento da cultura e, portanto, do limite de suas açōes e de sua intervenção social, a ponto de poder confirmar a concretização de sua atividade racional livre na universalização dos seus direitos e deveres de cidadão - foi transformado no principal componente ideológico da formação que aparenta ser o que de fato não é. 
O princípio burguês de individuação, cujas bases foram dolorosamente edificadas, se metamorfoseia em seu contrário, pois o engodo da personalidade bem estruturada não pode se eximir da necessidade de ser associado ao consumo de algum tipo de produto da Indústria Cultural, cuja elaboração pautou-se na mentira da primazia das necessidades básicas sobre as necessidades de consumo. Mas o indivíduo também sente que a possibilidade de usufruir da falsa experiência de ser reconhecido como "sujeito" pelos outros depende sobretudo dos signos dos bens de consumo que porta. Portanto, ele precisa se esforçar para continuar acreditando tanto na aparência da prioridade de suas necessidades básicas, no ato de consumo desses produtos, como no poder da sua vontade de se libertar completamente das amarras do trabalho entediante, a partir do momento em que, por exemplo, o riso sadomasoquista encontra seu espaço de legitimação na "divertida" comédia preconceituosa, servindo como um consolo que compensa a sua própria humilhação.

Desta feita, é equivocado o pensamento de que, quando abandonamos os locais de trabalho, podemos finalmente desfrutar momentos que permitam fazer com que nos identifiquemos como sujeitos de nossas ações. Cotidianamente repreendemos aqueles que, nessas ocasiões, nos lembram das enfadonhas situações de trabalho que são dominadas por seqüências de operações padronizadas. Todavia, esse devaneio se esvaece quando, diante de um olhar mais atento, percebemos que essas mesmas seqüências padronizadas estão também nas atividades de lazer, sem que tenhamos consciência disso. Os ritmos binários dos últimos hits são facilmente memorizados e fornecem a sensação do retorno a uma eterna banalidade.

Já os detalhes fungíveis que predominam nos mais "variados" filmes de ação, tais como a introdução musical numa seqüência da fita, fazem bem mais que nos tranqüilizar com a promessa de que o vilão terá um castigo merecido. Ambas as circunstâncias parecem estar dizendo que a vida possui sempre as mesmas tonalidades e que devemos nos habituar a seguir os compassos previamente demarcados. A provável sensação de monotonia é facilmente compensada pela felicidade de se sentir integrado.

Adorno e Horkheimer (1996, p. 28) já diziam que a "diversão é o prolongamento do trabalho no capitalismo tardio. Ela é procurada por quem quer escapar ao processo de trabalho mecanizado, para se por de novo em condições de enfrentá-lo". É interessante observar até que ponto o processo de mecanização atinge o cerne da nossa estrutura de personalidade, quando "inocentemente" dizemos a nós mesmos e aos outros que precisamos nos "desligar" do trabalho, assistindo ao filme que não exige muito esforço do pensamento, que promove o tão esperado relaxamento. Adorno desen- 
volve uma argumentação semelhante no texto "Tempo livre", ao comentar que a própria luta pela liberdade, bastante presente nos movimentos estudantis, foi muito bem capitalizada e funcionalizada pelas famosas indústrias do camping.

As pessoas são diariamente coagidas a exercerem algum tipo de atividade "livre". Mas a funcionalização do desejo encontra um exemplo ainda mais estarrecedor: Adorno identifica o absurdo, que não deixa de ter sua lógica na sociedade atual, de que o próprio bronzeamento da pele se transforma num fetiche. Mais do que servir para auxílio de um determinado flerte, a obrigatoriedade da tez bronzeada concerne ao necessário reconhecimento dos outros de que o indivíduo conseguiu se desvencilhar por algum tempo do trabalho, afirmando a sua pretensa liberdade. $\mathrm{O}$ reconhecimento da aparência de humanização denota a perpetuação da desumanização do indivíduo transformado em propaganda de si mesmo (Adorno, 1995, p. 74-75). E são essas pessoas que confundem de tal forma a personalidade com os ícones de consumo que têm mais chances de vivenciar o gosto do sucesso.

Em 1990, no congresso realizado em Berlim sobre atualidade do pensamento adorniano, Claussen já alertava para a possibilidade da própria teoria crítica ser engolfada pela Indústria Cultural nos chamados programas de auditório, bastante comuns também na televisão alemã e que pretendiam auferir o nível de "conhecimento" dos participantes que respondiam as questôes feitas com banalizados conceitos de filosofia. Adorno já dizia que o processo semiformativo, no qual o conceito foi apreendido de forma medíocre, não significa o cumprimento de um primeiro estágio que deverá ser ultrapassado. Na verdade, a absorção do banalizado continua sendo cada vez mais a inimiga mortal da formação (Adorno, 1996, p. 402).

Diante desse quadro, poder-se-ia concluir que a produção e reprodução da Indústria Cultural precisariam de consumidores passivos. Mas talvez fosse correto o raciocínio contrário: os indivíduos necessitam combater, principalmente em si próprios, de forma enérgica, qualquer tipo de práxis contrária à integração pelo consumo. Para poder ser passivo, o indivíduo deve antes vivenciar ativamente a negação de si mesmo.

Não deixa de ser doloroso constatar que o progresso da universalização da lógica do equivalente cada vez mais faz com que as possibilidades emancipatórias da cultura só se conservem na dimensão ideológica. Todavia, um procedimento crítico torna-se relevante, sobretudo quando a difusão da tecnologia fornece a sensação da efetiva democratização da produção cultural. Como pudemos observar anteriormente, o desejo de que as informaçóes 
veiculadas no plano global contribuam para a realização da emancipação ainda não se realizou. A Indústria Cultural afirma-se como princípio deseducativo cada vez mais. Faz-se necessária uma atitude de resistência frente a esse processo.

Trata-se de identificar na aparente democratização da produção simbólica o seu inerente potencial fascista. O preço pago pela ilusão da "inevitável" emancipação da condição de menoridade através do consumo dos produtos da Indústria Cultural precisa ser sentido, no íntimo, como sendo alto demais. Confirma-se, portanto, uma das principais hipóteses de Adorno e Horkheimer contidas na Dialética do esclarecimento: a exacerbação da Indústria Cultural - incrivelmente potencializada pelo avanço das forças produtivas do capitalismo transnacional - legitima a reincidência da barbárie.

A fissura entre a promessa da democratização da cultura e a conseqüente universalização da formação é fator indicativo da cumplicidade entre o discurso oficial emancipatório e as relaçōes materiais que se aferram na dominação e na exploração das naturezas interna e externa. A sociedade tecnificada, a qual se afasta cada vez mais da sua função original de contribuir para o fim das necessidades, exige a manutenção do sofrimento humano para a consagração de sua existência.

A reincidência da barbárie não é apenas observada nos atos mais explícitos, tais como o assassinato do índio pataxó, citado na introdução desse texto. Ela também é notada no sorriso conivente daquele "indivíduo" que acha graça na anedota preconceituosa, pois teme não ser considerado membro do grupo ao qual pertence caso não proceda dessa forma, ou mesmo no consumo de produtos simbólicos que incentivam a sexualidade precoce das crianças, que ainda não possuem as capacidades afetivas e cognitivas necessárias para poderem refletir que o modelo de sexualidade imposto pelo consumo desses produtos não pode ser considerado a única alternativa para a concretização do processo de individuação.

A opulência de um ego doentio é estimulada numa sociedade cujas bases da formação sofrem diariamente abalos talvez irreparáveis. Dessa forma, o entorpecimento que tantas vezes Adorno denunciou em seus textos é combatido não através daquele pedido de ajuda, o qual permitia ouvir o sussurro de um ego combalido que clamava pelo fim de sua própria debilidade. Ele é "contestado" por meio de mecanismos de defesa que comprazem aos ditames do consumo dos produtos "culturais", tais como os produtos que prometem o "rápido e milagroso" emagrecimento às custas da anorexia ou dos brincos e tatuagens colocados nos lábios e narinas dos jovens. 
$\mathrm{O}$ anseio de que essa sensação de insatisfação pode ser amainada pelas práticas sadomasoquistas, que já são verificadas com uma freqüência que não deve ser subestimada, precisa ser cada vez mais investigado por aqueles que não se conformam com a mentira que afirma a concretização da felicidade aqui e agora. É nesse sentido que a possibilidade da reapropriação das potencialidades emancipatórias da formação não se faz apenas desejada. Ela é uma das principais condiçôes de resistência à reprodução da dessensibilização e da barbárie. Ora, a reapropriação da capacidade de autocrítica da formação passa também por uma concepção educacional pautada nos escritos dos pensadores da chamada Teoria Crítica, sobretudo Theodor W. Adorno. A busca pela efetiva aproximação entre os desejos individuais e as regras e leis sociais deve ser baseada na constatação de que, na atual sociedade, observa-se um hiato muito grande entre os conteúdos das promessas de igualdade e suas respectivas realizaçôes. Essa crítica da ideologia também necessita estar presente durante a realização do educativo dentro ou fora das escolas. Não há mais como se aquietar diante da dissimulação do processo "formativo" atual que, desde o início, compraz sim à semiformação não ao sentido emancipatório da Bildung. Assim, fazse justiça àqueles que são cotidianamente injustiçados, exatamente porque suas existências desiguais são verdadeiramente afirmadas como tais, sem eufemismo. A luta pela verdadeira felicidade deve estar atrelada ao reconhecimento do estado atual de infelicidade.

É nesse sentido que uma concepção educacional que se julga crítica poderia contribuir para o processo de auto-reflexão da formação que se converteu em semiformação. Se essa concepção educacional também assume como sua a tarefa de auxiliar o exercício da crítica da ideologia, então talvez não fosse equivocado aludir à observação de Adorno de que também tem algo de prático a denúncia de que a exigência, cotidianamente reiterada, de submissão da teoria em relação à prática significa "anular o conteúdo da verdade e condenar a prática à loucura” (Adorno, 1992, p. 79). Nos dias atuais, torna-se cada vez mais relevante incentivar a autocrítica daqueles que se julgam educados, mas que colaboram decisivamente tanto para sua própria debilidade quanto para a dos outros.

Esta forma de conceber a educação poderia colaborar para a reprodução de um clima cultural que favorecesse aquela disposição de estimular a continuidade do conteúdo apreendido com a própria formação do indivíduo. O educador que faz sua autocrítica, ao se preocupar com a compreensão dos motivos que incentivam a distância entre as teorias sobre o preconceito e a práxis preconceituosa dos mesmos alunos, os quais memorizam os conteúdos mas não deixam de fazer anedotas racistas, por 
exemplo, trabalha para que o fosso entre o conceito e a práxis emancipadora não seja tão grande, apesar da sociedade atual incentivar exatamente a permanência desta distância. A concepção educacional que se pauta na denúncia da falsa reconciliação atual - a qual dissimula uma vida plena de liberdade, mas que prima pela sua ausência - fala também em nome da possível reconciliação entre aqueles conteúdos emancipatórios da formação e uma vida menos injusta. Uma vida cujo desejo verdadeiro de uma utilização mais humana da técnica não sirva como justificativa para a perpetuação do processo de industrialização da cultura, que prima pela regressão das capacidades humanas e, portanto, pela reincidência da barbárie.

\title{
Notas
}

1. Seria importante distinguir a opção de tradução de Habbildung por semiformação e não por pseudoformação. De acordo com Wolfgang Leo Maar: "Halbbildung é traduzida por semiformação justamente para tentar respeitar o sentido global que Adorno procuraria imprimir ao termo: ao mesmo tempo registra a limitação da finalização do processo - incompletude, pela metade - e a plena validade do processo formador como tal, ainda que travado. Essa última componente ficaria prejudicada na opção por 'pseudoformação', como a tradução castelhana, em que se indicaria um 'faz de conta' formativo, como se se tratasse de pretender algo que não é. A semiformação ocorre realmente, mas travada”. (Maar, 1992, p. 186). De fato, além da escolha pela utilização do termo semiformação conservar o sentido da falsidade do processo formador, há que se destacar a permanência da sutileza nessa escolha de tradução do conceito, pois a semiformação apresenta-se, de forma dissimulada, como a redentora do embrutecimento subjetivo do indivíduo, mas, na verdade, como já disse Adorno, é a inimiga mortal da formação (Bildung). O termo semiformação resguarda, no plano subjetivo, o sentido emancipatório da formação que se converteu em ideologia, em decorrência do crescente processo de hegemonia da Indústria Cultural, cujo conceito também apresenta, fato este que não é casual, uma certa ambigüidade por não ser apenas cultura ou indústria, ao mesmo tempo em que possui características de ambas.

2. Durante a ascensão nazista, mais especificamente na noite de 10 de novembro de 1938, houve uma destruição de lojas, moradias e sinagogas judaicas. Tal episódio ficou conhecido como a "noite dos cristais" (Wermke, 1996, p. 902).

\section{On the Actuality of the Concept of Culture Industry}

\begin{abstract}
This text holds that the concept of culture industry is actual and important to criticising the social conditions which universalizes a process of half culture. And it concludes that some Theodor W. Adorno's concepts could give elements to resist against this process which forms debilitated individualities.
\end{abstract}

Key words: Culture Industry; Culture; Half-Culture; Theodor W. Adorno; Critical Theory. 
Referências bibliográficas

ADORNO, Theodor W. "A Indústria Cultural". In: COHN (Org.), Theodor W. Adorno, Trad. de Amélia Cohn. Coleção Grandes Cientistas Sociais. São Paulo: Ática, 1986.

. "Anotaçōes sobre teoria e prática". In: RAMOS-DE-OliveIRA, N. Quatro textos clássicos. Trad. de Newton Ramos-de-Oliveira. São Carlos: UFSCar (publicação interna), 1992.

"Tempo livre". In: Palavras e sinais. Trad. de Maria Helena Ruschel, Petrópolis: Vozes, 1995.

. Teoria da semicultura. Trad. de Newton Ramos de Oliveira com a colaboração de Bruno Pucci e Cláudia de Moura Abreu. Educação \& Sociedade, Campinas: Papirus, ano XVII, dez. 1996.

ADORNO, Theodor W. \& HORKHEIMER, Max. Dialética do esclarecimento. Trad. de Guido Antonio de Almeida. Rio de Janeiro: Zahar, 1986.

CLAUSSEN, Detlev. "Fortzusetzen: Die Aktualität der Kulturindustriekritik Adornos”. In: Hager, F.\& PfüTze, H. (Hrsg.). Das unerhört Modernel Berliner Adorno-Tagung: Lüneburg zu Klampen, 1990.

MAAR, Wolfgang L. Lukács, Adorno e o problema da formação. Lua Nova - Revista de Cultura e Política no 27, São Paulo: Marco Zero, 1992.

WERMKE, Matthias. Duden - Deutsches Universalwörterbuch. Mannheim und Leipzig, Deutschland: Dudenverlag, 1996. 